\title{
Enrichment of breast cancer stem-like cells by growth on electrospun polycaprolactone- chitosan nanofiber scaffolds
}

This article was published in the following Dove Press journal:

International Journal of Nanomedicine

19 February 2014

Number of times this article has been viewed

\author{
Jennifer Sims-Mourtada' \\ Rohina A Niamat ${ }^{2}$ \\ Shani Samuel ${ }^{2}$ \\ Chris Eskridge ${ }^{2}$ \\ Eric B Kmiec ${ }^{1,2}$ \\ 'Center for Translational Cancer \\ Research, Helen F Graham Cancer \\ Center and Research Institute, \\ Christiana Care Health Services, Inc \\ Newark, ${ }^{2}$ Department of Chemistry, \\ Delaware State University, Dover, \\ DE, USA
}

\begin{abstract}
A small population of highly tumorigenic breast cancer cells has recently been identified. These cells, known as breast-cancer stem-like cells (BCSC), express markers similar to mammary stem cells, and are highly resistant to chemotherapy. Currently, study of BCSC is hampered by the inability to propagate these cells in tissue culture without inducing differentiation. Recently, it was reported that proliferation and differentiation can be modified by culturing cells on electrospun nanofibers. Here, we sought to characterize the chemoresistance and stem-like properties of breast cancer cell lines grown on nanofiber scaffolds. Cells cultured on three-dimensional templates of electrospun poly( $\varepsilon$-caprolactone)-chitosan nanofibers showed increases in mammary stem cell markers and in sphere-forming ability compared with cells cultured on polystyrene culture dishes. There was no increase in proliferation of stem cell populations, indicating that culture on nanofibers may inhibit differentiation of BCSC. The increase in stemness was accompanied by increases in resistance to docetaxel and doxorubicin. These data indicate that BCSC populations are enriched in cells cultured on electrospun $\operatorname{poly}(\varepsilon$-caprolactone)-chitosan nanofibers, scaffolds that may provide a useful system to study $\mathrm{BCSC}$ and their response to anticancer drug treatment.
\end{abstract}

Keywords: breast cancer, mammary stem cells, chemoresistance, nanofibers, three-dimensional culture

\section{Introduction}

Breast cancers contain a hierarchical pool of cells driven by a small population of self-renewing cells that resemble mammary stem cells. Breast cancer stem-like cells (BCSC), first characterized by the surface markers CD $44^{+} / \mathrm{CD} 24^{-/ \text {low }}$, are highly tumorigenic and are capable of undergoing self-renewal as well as differentiation. ${ }^{1,2}$ Inoculation of small numbers of CD $44^{+} / \mathrm{CD} 24^{-/ \text {low }}$ breast cancer cells in NOD/SCID mice can recapitulate the phenotypic heterogeneity of the parent tumor, ${ }^{1,2}$ whereas more differentiated cells lacking the $\mathrm{CD} 44^{+} / \mathrm{CD} 24^{-/ \text {low }}$ phenotype have a greatly reduced tumor-forming capacity. ${ }^{1,2}$ BCSC are more resistant to standard chemotherapy than more differentiated breast cancer cells. ${ }^{3-5}$ Although the bulk of tumor cells can be killed by standard treatments, BCSC remain and eventually regrow the tumor. There is a clinical need for new agents which either eradicate BCSC or skew them towards a differentiation pathway so that they become susceptible to standard treatments.

The mechanisms regulating the switch from self-renewal to differentiation are not clearly understood, and study of BCSC has been limited by the inability to propagate these cells without inducing differentiation. Additionally, BCSC self-renewal and maintenance are heavily influenced by the tumor microenvironment. Cell to cell
Correspondence: Jennifer Sims-Mourtada Center for Translational Cancer Research, Helen F Graham Cancer Center and Research Institute, Christiana Care Health Services, Inc, 470I Ogletown Stanton Rd Suite 4300, Newark, DE 19713, USA

$\mathrm{Tel}+\mathrm{I} 3026234648$

Fax + I 3026234314

Email jsimsmourtada@christianacare.org 
communications with breast stromal cells and interactions within the extracellular matrix influence BCSC properties; ${ }^{6-8}$ interactions with extracellular matrix proteins have been shown to prevent differentiation of cancer stem cells. ${ }^{8}$ Traditional two-dimensional culture systems are inadequate to study these interactions as they fail to reproduce the cell-cell interactions and three-dimensional complexity of solid tumors. Recently, three-dimensional scaffolds have been developed to mimic the architecture of extracellular matrix and the three-dimensional environment of tissues. Scaffolds of electrospun nanofibers can facilitate cell to cell communication $^{9}$ and can mimic cellular interactions by providing an increased surface to volume ratio with a high porosity similar to that of the extracellular matrix. ${ }^{10,11}$ Electrospinning allows the modification of nanofiber surfaces with natural or synthetic polymers to recapitulate the in vivo environment. ${ }^{12}$ Extracellular matrix proteins including collagen, ${ }^{13}$ elastin, ${ }^{14}$ and fibrinogen ${ }^{15}$ as well as synthetic polymers such as poly ( $\varepsilon$-caprolactone) (PCL), ${ }^{16}$ poly(lactic-co-glycolic) acid,,${ }^{17}$ and chitosan $^{18}$ (CS) can be combined to replicate the structural complexity of tissue.

PCL is a synthetic hydrophobic polymer widely used in biomedical and drug delivery devices. Its slow degradation kinetics, biocompatibility, and semicrystalline nanofibers simulate the extracellular matrix and provide a good scaffold for cell growth and engineering. ${ }^{19} \mathrm{CS}$ is a naturally occurring polysaccharide derived from $\mathrm{N}$-deacetylation of chitin. It is known to have excellent biocompatibility and biodegradability, which makes it an attractive material to use for biomedical applications, including bone tissue regeneration, wound dressings, and biosensors. ${ }^{20,21}$ Products made with CS alone, however, show poorly controlled mechanical strength and degradation in wet mediums. ${ }^{22}$ This environmental issue reduces its usage capabilities in biological solutions in the long term. To improve mechanical strength and slow the degradation rate, a blend of CS and PCL combines the biocompatibility and variability of CS materials with the tensile strength and hydrophobicity of PCL.

CS can vary by average molecular weight and percent of acetyl groups on the polymer backbone; CS can generally be found commercially as low or medium average molecular weight and with a $\geq 75 \%$ degree of deacetylation. Although CS scaffolds are created using a variety of molecular weight averages, it has been reported that low molecular weight CS does not form electrospun fibers at all and fibers synthesized from higher molecular weights contain large beads along the length of the fiber. ${ }^{23}$ We followed this rationale previously in choosing a variety of electrospun fiber membranes for growth of genetically modified cells. ${ }^{24}$ PCL-CS fibers were found to be the most consistent in facilitating cell growth and proliferation up to 96 hours post plating, maintaining a more robust structure than the other composite fibers examined. The reduced rate of replication (at 168 hours), without compromising viability, was an important aspect in our choice of PCL-CS as the scaffold for stem cell cultures. Dhiman et $\mathrm{al}^{25}$ also used three-dimensional CS scaffolds to grow MCF-7 cells successfully and set the stage for anticancer drug screening.

In general, nanofibrous mediums provide a threedimensional scaffold that puts seeded cells into a structure similar to that found in the body. Although many studies have reported growth of normal tissues on an electrospun scaffold, little is known about the growth of tumor cells on these fibers. In this study, we report that growth of breast cancer cell lines on PCL-CS nanofibers resulted in increased chemoresistance while enriching the population of BCSC.

\section{Materials and methods Preparation of fibers}

PCL (molecular weight 80,000) and CS (medium molecular weight) were purchased from Sigma-Aldrich (St Louis, MO, USA) and used without further purification. Ten percent (w/v [weight/volume]) PCL solution was prepared in 1,1,1,3,3,3-hexafluoro-2-propanol. A 0.5\% (w/v) CS solution was prepared in 1,1,1,3,3,3-hexafluoro-2-propanol. Both solutions were sonicated for 3 hours, left overnight, and sonicated for a further hour to ensure dissolution of all solid materials. PCL-CS solutions were prepared by mixing the prepared PCL and CS solutions in equal ratio and vortexing for one minute before use. PCL-CS fibers were fabricated using an electrospinning apparatus containing a stationary plate (outer dimensions $12 \mathrm{~cm} \times 8 \mathrm{~cm}$; inner gap dimensions $9.5 \mathrm{~cm} \times 2.5$ $\mathrm{cm}$ ) covered with aluminum foil at a distance of $10.5 \mathrm{~cm}$ from the syringe tip. Next, $1 \mathrm{~mL}$ of solution was loaded into a $5 \mathrm{~mL}$ syringe equipped with a 21 gauge needle. A voltage of $15.0 \mathrm{kV}$ was applied with a flow rate of $0.4 \mathrm{~mL}$ per hour. The electrospinning process was stopped when fiber formation in the inner gap showed visually dense fiber accumulation when tested with natural light. Quantification of fiber density on the microscope slide is difficult with the selected method and fiber recovery plate. Therefore, visual measurements were made to confirm similar fiber densities between samples.

\section{Fiber fixation}

Aligned nanofibers were adhered to microscope cover slips by applying Silicone adhesive (Nusil Silicone Technology, 
Carpentaria, CA, USA) in an approximately $2 \mathrm{~mm}$ thickness around the outer perimeter of microscope cover slip, gently placed onto the aligned fiber area in the stationary plate inner gap, and left to cure for 20 minutes before cutting out the aligned section. Fibers were sterilized with $10 \%$ penicillin/ streptomycin in isopropanol solution under ultraviolet light for 4 hours and coated with $200 \mu \mathrm{L}$ of fibronectin.

\section{Microscopy of fibers}

Scanning electron microscopy was used to image the PCL-CS fibers and determine the average fiber diameter. The fiber membranes were adhered to an aluminum mount-M4 (cat \# 75610, Electron Microscopy Sciences, Hatfield, PA, USA) and coated with Au/Pt using a Denton Benchtop Turbo III carbon evaporator (Denton Vacuum, Moorestown, NJ, USA) prior to imaging under a Hitachi S4700 field-emission scanning electron microscope (Hitachi High Technologies, Tokyo, Japan) with magnification between 5,000 and 15,000. Fiber diameters were determined using ImageJ software (version 1.45; National Institute of Health, Bethesda, MD, USA).

\section{Cell culture}

The cell lines were obtained from the American Type Culture Collection (Manassas, VA, USA) and maintained in Dulbecco's Modified Eagle's Medium (Invitrogen, Carlsbad, CA, USA) containing 10\% fetal bovine serum (Fisher Scientific, Pittsburg, PA, USA), $0.01 \mathrm{mg} / \mathrm{mL}$ human recombinant insulin (Invitrogen) and antibiotic-antimycotic solution (Invitrogen), and maintained at $37^{\circ} \mathrm{C}$ under $5 \% \mathrm{CO}_{2}$ in a humidified incubator. Unless otherwise stated, cells were seeded at a density of 50,000 cells and grown on nanofiber scaffolds or polystyrene culture dishes for 72 hours. To capture only those cells growing on the fibers, the fiber ring and the attached cells were removed and transferred to a fresh well, rinsed with phosphate-buffered saline, and the cells were removed by trypsinization. Cell viability and size were determined using a Countess automated cell counter (Invitrogen) after staining with Trypan blue (Invitrogen).

\section{Immunofluorescence analysis}

Cells grown on the nanofiber scaffolds or polystyrene dishes were trypsinized as described above, washed with phosphate-buffered saline containing $5 \%$ fetal bovine serum, and resuspended at a density of $1 \times 10^{6}$ cells $/ \mathrm{mL}$ in cold phosphate-buffered saline with $5 \%$ fetal bovine serum. Cells were stained with phycoerythrin-conjugated CD44 and fluorescein isothiocyanate-conjugated CD24 (Abcam, Cambridge, MA, USA) for 30 minutes at room temperature.
The samples were centrifuged, washed, and passed through a BD Falcon cell strainer cap tube (BD, Franklin Lakes, NJ, USA) for fluorescence-activated cell sorting analysis. For proliferation experiments, samples were stained using a Click-iT ${ }^{\circledR}$ EDU flow cytometry kit (Invitrogen), followed by staining with CD44 and CD24 according to the manufacturer's instructions. Samples were analyzed on a fluorescenceactivated cell sorting Aria II flow cytometer (BD) and were gated on an unstained control. For triple staining procedures, compensation was performed with single stained cells to decrease overlaps of fluorophore emission spectrums.

\section{Mammosphere-forming assays}

Cells were removed by trypsinization after culture on PCLnanofiber scaffolds, and washed with culture medium, followed by washes with phosphate-buffered saline. Cells were resuspended in Minimum Essential Medium supplemented with $1 \times \mathrm{B} 27,20 \mathrm{ng} / \mathrm{mL}$ epidermal growth factor, and $20 \mathrm{ng} / \mathrm{mL}$ basic fibroblast growth factor (all from Invitrogen). Cells were seeded into ultra-low attachment plates (Corning Life Sciences, Salt Lake City, UT, USA) at a density of 1,000-2,000 cells per well. Cells were grown for 10-14 days and spheres were counted using an EVOS FL microscope (AMG Micro, Bothell, WA, USA) at 10× magnification. The data are represented as sphere-forming efficiency (spheres counted/cells plated). Statistical analysis was performed using the unpaired Student's $t$-test with Prism 6 software (Graph Pad, La Jolla, CA, USA).

\section{Chemoresistance assays}

Cells were seeded at a density of 50,000 cells and grown on nanofiber scaffolds or polystyrene culture dishes for 72 hours. Cells were removed by trypsinization and replated at a density of 7,000 cells per well in a 96-well plate and cultured overnight. Cells were treated with docetaxel or doxorubicin at the indicated concentrations and assayed for survival 48 hours later using the 3-[4,5-dimethylthiazol-2-yl]-2,5 diphenyl tetrazolium bromide (MTT) cell viability kit assay (Biotium Inc, Hayward, CA, USA). Data are represented as percent of untreated cells. The statistical analysis was performed using an unpaired Student's $t$-test with Prism 6 software (GraphPad).

\section{Results}

\section{Microscopy of fibers}

Field-emission scanning electron microscopy was used to visualize the morphology and density of the PCL-CS fibers in an attempt to maintain some level of consistency from 
batch to batch. Aligned PCL-CS fibers showed a largely smooth morphology with some evidence of areas with larger diameters (Figure 1). With this method, an average fiber diameter could be determined through image analysis. Fibers had a remarkably tight average diameter of $432 \pm 207 \mathrm{~nm}$.

\section{Growth of breast cancer \\ cell lines on nanofiber scaffolds}

Aligned electrospun nanofiber scaffolds were prepared from $10 \%(\mathrm{w} / \mathrm{v})$ PCL electrospun in equal ratio with $0.5 \%(\mathrm{w} / \mathrm{v})$ CS. Physical characterization of PCL-CS fibers has been previously reported. ${ }^{26} \mathrm{~A}$ 1:1 ratio of PCL to $\mathrm{CS}$ has been reported to merge the high mechanical strength properties of PCL with the biocompatibility of CS polymers. We decided to examine the growth of cells on plastic culture dishes and PCL-CS nanofibers by microscopy, focusing initially on cell morphology. MCF-7 and T47-D breast cancer cells were plated or positioned on fibers at a density of 50,000 cells per sample, and after 48 hours, cell morphology was evaluated (Figure 2). Cells grown on two-dimensional polystyrene plates demonstrated clear trigonal morphologies, characteristic of a normal proliferation pattern. Cells cultured on nanofibers, however, appeared elongated and smaller than those cultured twodimensionally; an average diameter of $10.4 \pm 0.735$ microns was measured compared with $16.3 \pm 0.490$ microns for cells on polystyrene cultures. Cells expanding on nanofibers adopt a somewhat aligned configuration, reflecting the structure of the nanofiber to some degree. Cell viability, as determined by Trypan blue exclusion, was not affected by growth on fibers at 72 hours.

\section{Enrichment of BCSC populations in cells cultured on PCL-CS nanofiber scaffolds}

Interactions with extracellular matrix proteins have been shown to increase the stemness of tumor cells. ${ }^{8}$ We sought to determine if increases in BCSC could be observed in breast cancer cell lines grown on PCL-CS nanofibers. High expression of CD44 and low expression of CD24 are commonly used to identify BCSC in human cell lines. ${ }^{27}$ These biomarkers are associated with increased resistance to chemotherapy, ${ }^{3-5}$ tumorigenesis, ${ }^{1}$ and poor prognosis. ${ }^{28,29}$ Therefore, we sought to determine if culture on nanofiber scaffolds could increase the $\mathrm{CD} 44^{+} / \mathrm{CD} 24^{- \text {llow }}$ population. Doubling times for the $\mathrm{CD} 44^{+} / \mathrm{CD} 24^{-/ \text {low }}$ population of $\mathrm{MCF}-7$ and T47-D cell lines have been reported to occur between 50 and 72 hours; therefore, we chose to examine numbers of stem cells after 72 hours of growth on fibers. ${ }^{30} \mathrm{MCF}-7$ and T47-D cells were plated onto PCL-CS scaffolds and grown for 72 hours. Cells were then analyzed for breast cancer stem cell surface markers CD44 and CD24 by fluorescence-activated cell sorting. ${ }^{1}$ As shown in Figure 3, an increase in the $\mathrm{CD} 44^{+} / \mathrm{CD} 24^{- \text {low }}$ population was observed in both lines compared with control cells grown in polystyrene dishes, indicating enrichment of BCSC on three-dimensional culture. To confirm that culture on nanofiber scaffolds increases the BCSC population, we also performed mammosphere-forming assays. The capacity to form nonadherent spheres (mammospheres) is increased in early progenitor/stem cells and is often used as an indirect measurement of self-renewing capability; ${ }^{31}$ thus, the number of spheres is a correlate of the proportion of BCSC. Cells were grown on nanofibers or polystyrene surfaces for 72 hours and then gently removed from the matrix. Cells were then plated in mammosphere cultures for 10-14 days, after which time developing spheres (mammospheres) were counted using an EVOS FL microscope at a magnification of $10 \times$. Consistent with the increase in BCSC markers, a statistically significant increase in mammosphere formation (and number) was observed in cells grown on the nanofiber scaffolds as compared with those grown on the polystyrene surface (Figure 4).
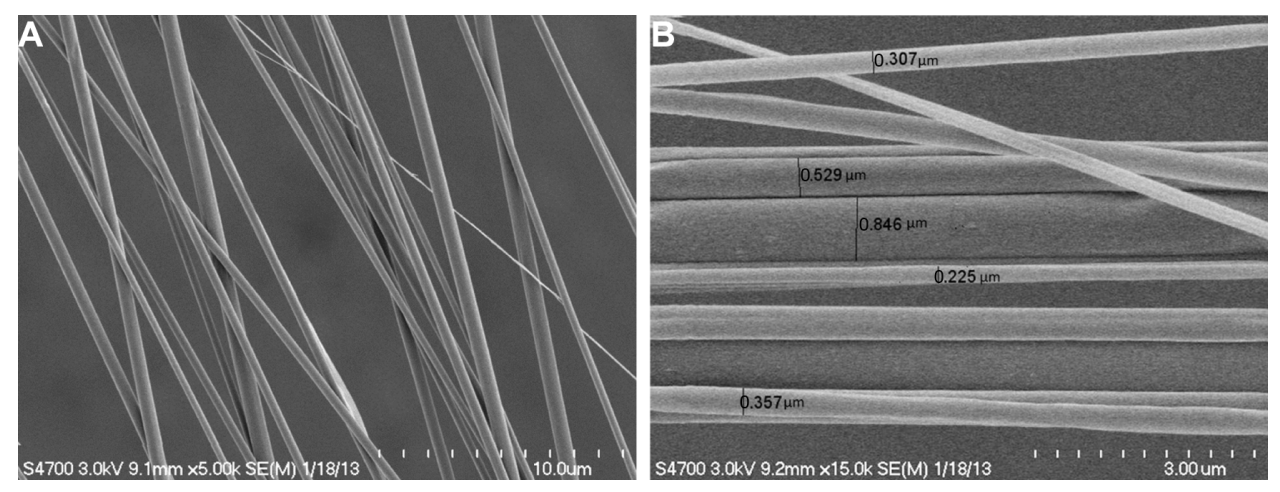

Figure I Scanning electron microscopy images of polycaprolactone-chitosan fibers at 5,000×(A) and I5,000× (B) zoom. Note: Fiber diameters were calculated based on $3 \mu \mathrm{m}$ scale bar located on the lower right hand corner of the image (B). 
T47-D

A

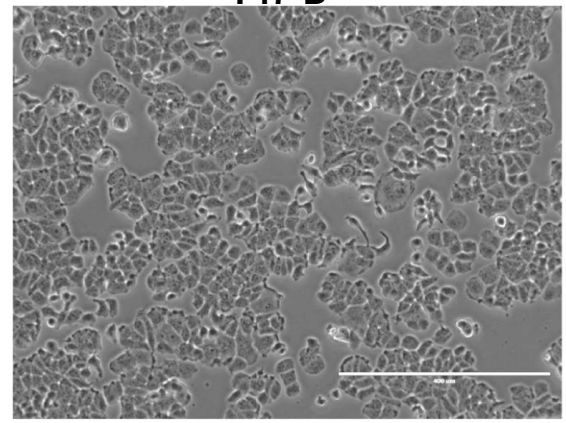

C

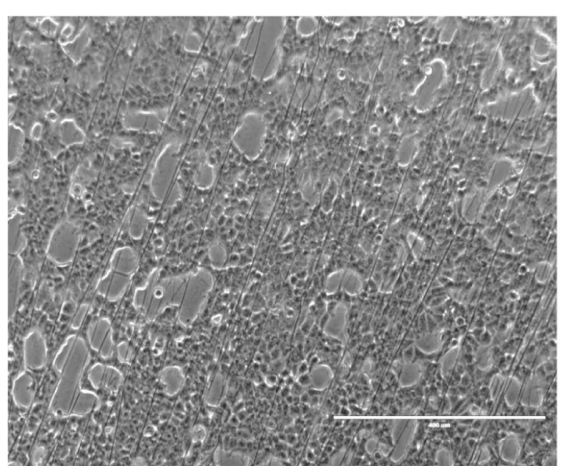

MCF-7

B

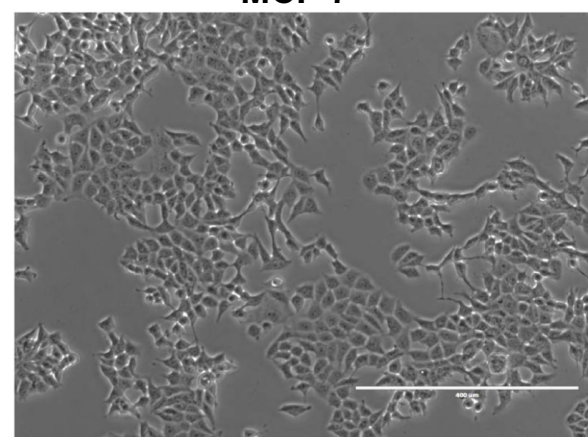

D

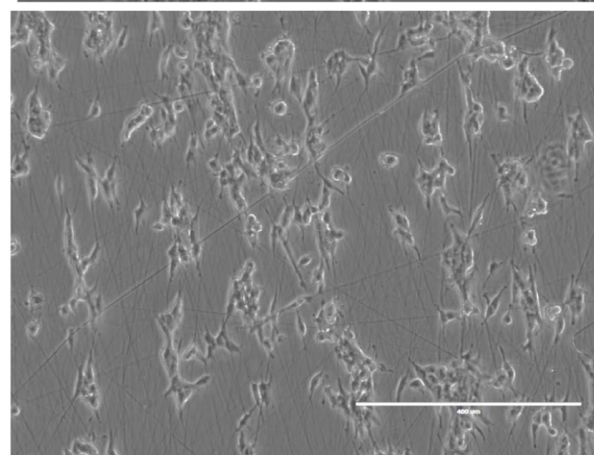

Figure 2 T47-D or MCF-7 cells grown in plastic culture dishes (A and B) and on PCL chitosan nanofibers (C and D) for 48 hours.

Note: Changes in cell morphology were evaluated using an EVOS FL microscope (AMG Micro, Bothell, WA, USA) at a magnification of I0×.

Abbreviation: PCL, polycaprolactone.

A
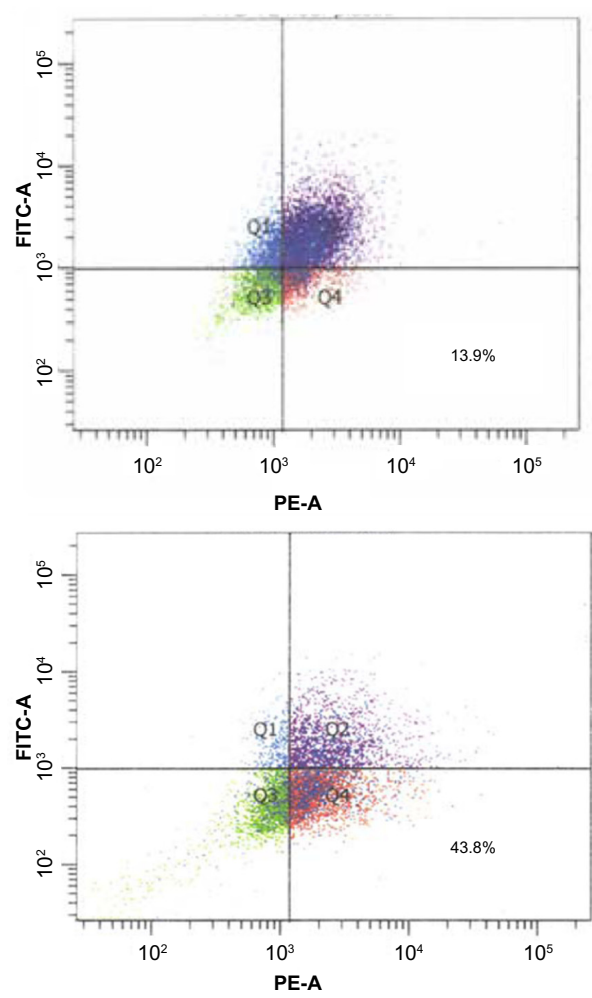

B

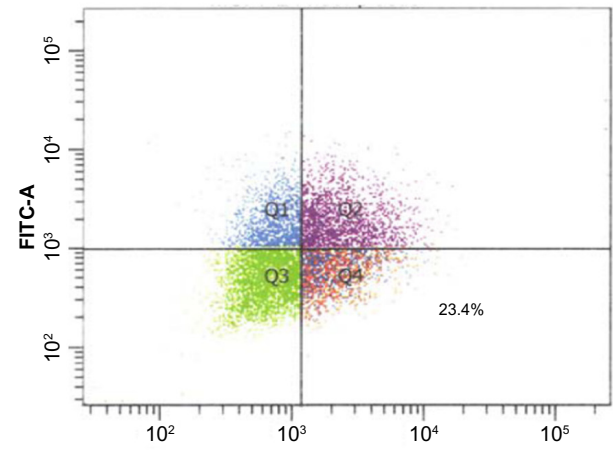

PE-A

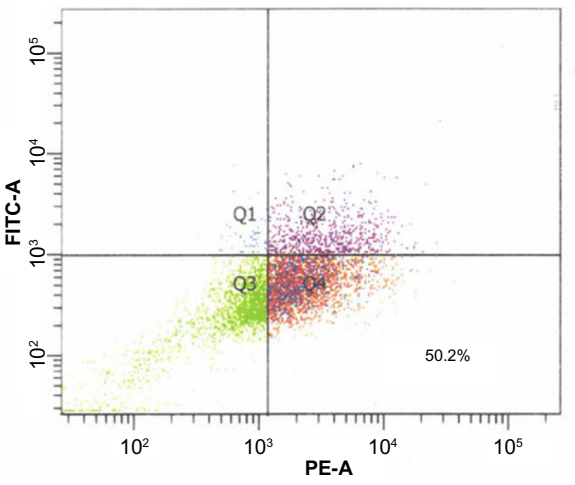

Figure 3 Expression of $\mathrm{CD} 44^{+} / \mathrm{CD} 24^{- \text {llow }}$ cell surface markers under compatible growth conditions.

Notes: T47-D (A) and MCF-7 (B) cells were grown in plastic culture dishes (upper panels) or polycaprolactone-chitosan nanofibers (lower panels) for 72 hours. An increase in $\mathrm{CD} 44^{+} / \mathrm{CD} 24^{- \text {llow }}$ cells is observed in cells cultured polycaprolactone-chitosan nanofibers. Data are representative of two separate experiments. Abbreviations: FITC-A, fluorescein isothiocyanate; PE-A, phycoerythrin. 


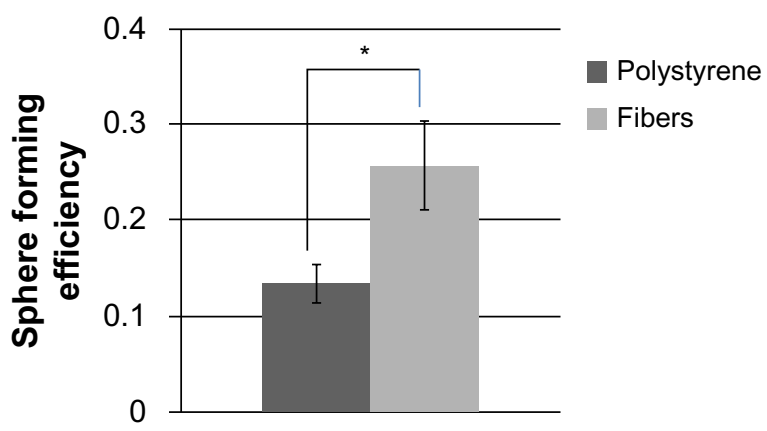

Figure $\mathbf{4}$ Sphere formation is increased after culture on polycaprolactone-chitosan nanofibers.

Notes: Cells were plated on nanofibers or polystyrene dishes for 72 hours, and removed and plated in mammosphere cultures. The ability to form mammospheres in MCF-7 cells after culture on polycaprolactone-chitosan nanofibers is compared with control cells cultured in polystyrene dishes. Data are expressed as sphere forming efficiency (spheres counted/cells plated). *Significant difference $(P \leq 0.05)$.

\section{Proliferation rates of cells cultured on PCL-CS scaffolds}

Increases in BCSC populations could result from either increased proliferation of $\mathrm{CD} 44^{+} / \mathrm{CD} 24^{-/ \text {low }}$ populations (self-renewal) or inhibition of BCSC differentiation. To determine proliferation rates of stem and nonstem cell subpopulations, we performed a tricolor analysis of $\mathrm{CD} 44^{+} /$ CD24-low surface marker expression, coupled to 5-ethynyl2'-deoxyuridine (EdU) incorporation, using flow cytometry. The EdU incorporation assay is related to the 5-bromo-2'deoxyuridine (BrdU) replication assays; this molecule is readily integrated into elongating DNA replication forks as a function of DNA polymerase activity. ${ }^{32}$ Once incorporated, these molecules can be detected by fluorescent antibodies, an assay recognized as a sensitive and definitive measure for cell proliferation. Although a slight decrease in proliferation rates was observed in nonstem cell populations, there was no significant change in the numbers of proliferating BCSC grown on nanofibers as compared with cells grown on a plain surface (Table 1). It is likely then, that in this system, growing these cells on nanofibers reduces the rate or extent of stem cell differentiation.

Table I Culture on polycaprolactone-chitosan fibers does not increase proliferation of breast-cancer stem-like cells

\begin{tabular}{|c|c|c|c|c|}
\hline & \multicolumn{2}{|l|}{ MCF-7 } & \multicolumn{2}{|l|}{ T47-D } \\
\hline & Polystyrene & Fiber & Polystyrene & Fiber \\
\hline Total population & 38.7 & 31.5 & 22.2 & 21.5 \\
\hline $\mathrm{CD} 44^{+} / \mathrm{CD} 24^{-}$ & 31 & 23.8 & 21.5 & 23.5 \\
\hline
\end{tabular}

Notes: MCF-7 and T47-D cells were grown on nanofibers or polystyrene dishes for 72 hours and analyzed by tricolor fluorescence-activated cell sorting. Numbers of proliferating cells were determined in the total cellular population and in the breastcancer stem-like cell compartment $\left(\mathrm{CD}^{4} 4^{+} / \mathrm{CD}^{2} 4^{- \text {-low }}\right)$. Data are expressed as the percentage of S-phase cells as determined by EDU incorporation. This experiment was performed in duplicate with similar results.

\section{Enhanced chemoresistance of cells cultured on PCL-CS scaffolds}

$\mathrm{BCSC}$ are reported to be highly resistant to chemotherapeutic agents $^{3-5}$ and so we next sought to determine if the increase of BCSC populations in three-dimensional culture is associated with a decreased response to some anticancer drugs. Cell lines were cultured on nanofiber scaffolds or polystyrene culture dishes for 72 hours. The cells were then placed in 96-well plates and tested for resistance to docetaxel or doxorubicin for a period of 48 hours. Viability was determined for all cell samples by using an MTT viability assay. The results, presented in Figure 5, reveal a significant increase in resistance to the cytotoxic effects of docetaxel and doxorubicin when cells are cultured on three-dimensional scaffolds but not on two-dimensional polystyrene cultures. As a function of exposure to increased drug concentration, a higher level of cells remain viable if grown on PCL-CS nanofibers.

\section{Discussion}

The mammary epithelium is a dynamic, complex tissue that is composed of multiple cell types as well as an extracellular matrix. Many aspects of both normal and malignant breast tissues are not fully understood, and their study has been limited by the lack of physiologically relevant culture methods. For the last few decades, breast cancer has been investigated through the use of cell lines grown in monolayer cultures often in polystyrene dishes. These lines have either been studied ex vivo or implanted into animal models for subsequent in vivo studies. This approach or protocol has resulted in identification of novel therapeutic approaches, but few of these have translated into clinically relevant therapeutics. Alterations in cell morphology and gene expression have been observed in cells cultured in two-dimensional models compared with those grown in vivo. ${ }^{33,34}$ This is thought to be due to the absence of tissue-specific architecture as well as loss of signaling from the extracellular matrix..$^{34,35}$ As an alternative to two-dimensional culture methods, three-dimensional scaffolds have been developed as culture mediums that, due to their inherent structure, resemble tumor architecture, enabling many interactions in the extracellular matrix that appear to be critical for cell growth to engage.

Aligned fiber scaffolds were used in this experiment to culture MCF-7 cells. Randomly aligned fibers were not chosen because MCF-7 and other breast cancer cells have been shown to grow more productively on aligned fibers ${ }^{36}$ when compared with randomly aligned fibers. Fiber density in this experiment was measured visually due to the type of collector plates available. Typically, higher fiber densities 


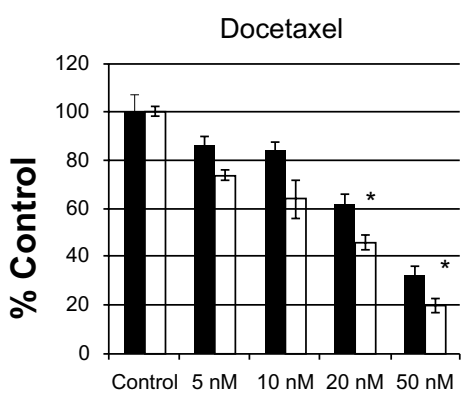

$\square$ Fibers
$\square$ Polystyrene

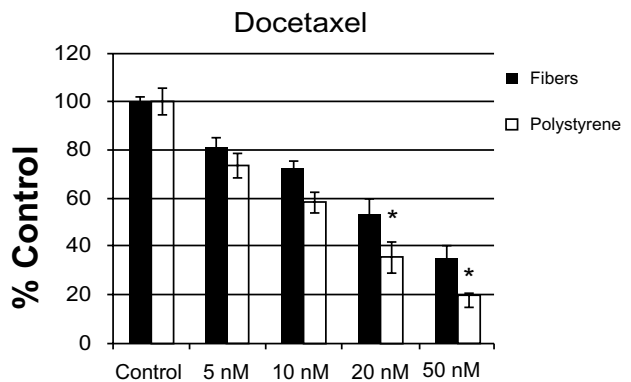

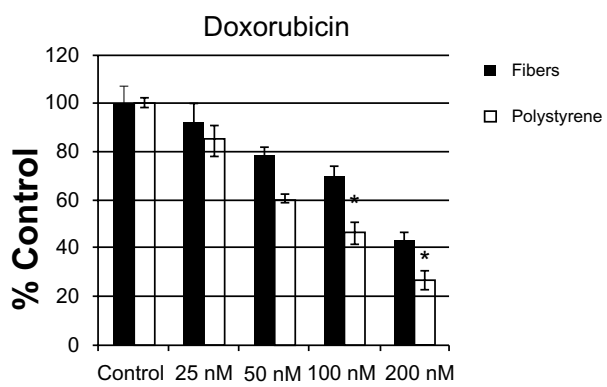

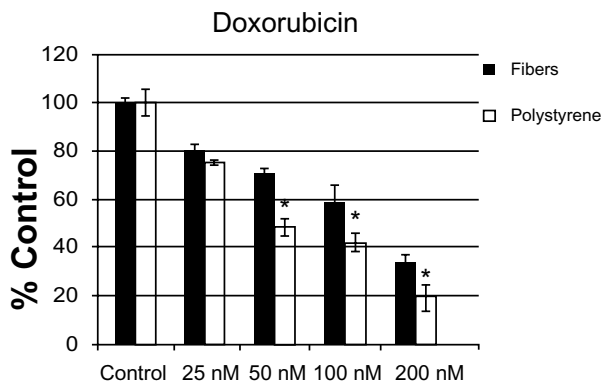

Figure 5 Culture on polycaprolactone-chitosan nanofibers results in increased resistance to chemotherapy.

Notes: MCF-7 cells (top panel) and T47D cells (lower panel) were cultured on polycaprolactone-chitosan nanofibers or in polystyrene dishes for 72 hours and then exposed to chemotherapy for 48 hours. Data are expressed as percentage of untreated cells as determined by 3-[4,5-dimethylthiazol-2-yl]-2,5 diphenyl tetrazolium bromide (MTT) assay. *Significant difference $(P \leq 0.05)$.

could be better controlled with a rotating drum collector or by using randomly aligned fibers.

Culture of breast cancer cells on substrates containing components of the extracellular matrix has been shown to alter gene expression, ${ }^{37}$ membrane receptor expression, ${ }^{38}$ and apoptotic potential in response to chemotherapeutics. ${ }^{39}$ Similarly, increased resistance to the antiestrogen agent tamoxifen was observed in MCF-7 breast cancer cells grown on three-dimensional CS matrices compared with monolayer culture. ${ }^{25}$ This increase in resistance was shown to be due to changes in cellular metabolism in cells grown on polymer scaffolds; metabolism of MCF-7 cells grown in threedimensional matrices resembled cellular metabolism of breast cancer cells grown in vivo. Although this study shows that three-dimensional growth induces cellular changes in MCF-7 cells, the effect of three-dimensional growth on BCSC populations or chemotherapeutic resistance is not described. Our study reveals changes in numbers of BCSC and emphasizes the importance of incorporation of three-dimensional model systems into drug screening protocols.

As the hierarchal nature of breast cancer becomes increasingly apparent, multiple studies are underway to develop novel drugs which selectively target BCSC with a minimal effect on normal mammary stem cells. ${ }^{40}$ Phenotypic and functional characteristics of both normal mammary stem cells and BCSC are difficult to study in traditional two-dimensional culture models, because these cells continually undergo differentiation. Propagation of BCSC in nonadherent spheres has yielded valuable information regarding pathways required for stem cell self-renewal. However, these culture methods are limited by the requirement for growth factor supplements, such as epidermal growth factor and fibroblast growth factor. ${ }^{31}$ Although these factors increase BCSC selfrenewal, they may also activate survival pathways which can artificially increase drug resistance. ${ }^{41,42}$ Nanofiber scaffolds may offer an alternative to mammosphere culture as a way to propagate BCSC in vitro. The composition of these fibers can be controlled or modified to either inhibit or promote cellular differentiation. ${ }^{11,43,44}$ In this study, we show that breast cancer cell lines cultured on PCL-CS nanofiber scaffolds enable enrichment in stem cell markers and enhance the formation of mammospheres. Since there was no increase in proliferation rates of the BCSC population, we suggest that the enrichment in BCSC arises from an inhibition of differentiation rather than an increase in self-renewal.

Similar increases in stem cell markers have been reported on MCF-7 cells cultured on collagen fibers. ${ }^{45}$ Culture of cells on collagen scaffolds for nine days was shown to increase the percentage of $\mathrm{CD} 44^{+} / \mathrm{CD} 24^{-/ \text {low }}$ cells by approximately 9-fold, as well as increase transcription of genes regulating epithelial-mesenchymal transition. Additionally, this study demonstrated that cells grown in three-dimensional culture had high tumorigenicity and formed larger tumors in vivo than their two-dimensional counterparts. While our study did 
not address gene expression profiling, we observed 2-3-fold increases in $\mathrm{CD} 44^{+} / \mathrm{CD} 24^{-/ \text {low }}$ populations after short-term (72-hour) culture on PCL-CS fibers. Although increases in BCSC phenotype and mammosphere formation were observed in our study after 72 hours of growth on fibers, the effect of longer-term culture (9 days) or increases in in vivo tumorigenic capability of cells cultured on three-dimensional nanofiber scaffolds is not known. The increase in BCSC phenotype and functionality was accompanied by a significant increase in resistance to chemotherapy. We propose that this increase in chemoresistance is due to increased numbers of resistant BCSC. Because the chemotherapeutic agents used in the experiment targeted mitotic cells, it is also possible that the increase in chemoresistance could be due, at least in part, to decreased proliferation rates in cells grown on PCL-CS fibers. However, decreased proliferation was only observed in the MCF-7 cell line; the fold changes in proliferating cells were similar in BCSC and total cell populations in this line. There was no decrease observed in either population in T47-D cells, suggesting that chemoresistance at least in this line is not due to changes in cellular proliferation after nanofiber culture. To our knowledge, this is the first report of increased chemotherapy resistance of breast cancer cells cultured on nanofiber scaffolds. This study demonstrates that electrospun PCL-CS nanofibers may provide a useful culture system for propagation of BCSC. We propose that these scaffolds may be useful to study BCSC properties, as well as to screen new therapeutic agents targeting cancer stem cell populations since a clear increase in BCSC populations was observed in this study. Further studies of nanofiber characteristics including alignment, density, and porosity are underway to optimize this culture method for drug screening applications.

\section{Acknowledgments}

The authors wish to thank the Flow Cytometry Core at the Helen F Graham Cancer Center and Research Institute. This project was supported in part by the Delaware INBRE program, with a grant from the National Institute of General Medical Sciences (8 P20 GM103446-13) from the National Institutes of Health.

\section{Disclosure}

The authors report no conflicts of interest in this work.

\section{References}

1. Al-Hajj M, Wicha MS, Benito-Hernandez A, Morrison SJ, Clarke MF. Prospective identification of tumorigenic breast cancer cells. Proc Natl Acad Sci U S A. 2003;100(7):3983-3988.

2. Clarke MF. Self-renewal and solid-tumor stem cells. Biol Blood Marrow Transplant. 2005;11(2 Suppl 2):14-16.
3. Li X, Lewis MT, Huang $\mathrm{J}$, et al. Intrinsic resistance of tumorigenic breast cancer cells to chemotherapy. J Natl Cancer Inst. 2008;100(9): 672-679.

4. Tanei T, Morimoto K, Shimazu K, et al. Association of breast cancer stem cells identified by aldehyde dehydrogenase 1 expression with resistance to sequential paclitaxel and epirubicin-based chemotherapy for breast cancers. Clin Cancer Res. 2009;15(12):4234-4241.

5. Fillmore CM, Kuperwasser C. Human breast cancer cell lines contain stem-like cells that self-renew, give rise to phenotypically diverse progeny and survive chemotherapy. Breast Cancer Res. 2008;10(2):R25.

6. Tsuyada A, Chow A, Wu J, et al. CCL2 mediates cross-talk between cancer cells and stromal fibroblasts that regulates breast cancer stem cells. Cancer Res. 2012;72(11):2768-2779.

7. Ghajar CM, Bissell MJ. Extracellular matrix control of mammary gland morphogenesis and tumorigenesis: insights from imaging. Histochem Cell Biol. 2008;130(6):1105-1118.

8. Hale JS, Li M, Lathia JD. The malignant social network: cell-cell adhesion and communication in cancer stem cells. Cell Adh Migr. 2012;6(4): 346-355.

9. Pham QP, Sharma U, Mikos AG. Electrospinning of polymeric nanofibers for tissue engineering applications: a review. Tissue Eng. 2006;12(5):1197-1211.

10. McLane JS, Schaub NJ, Gilbert RJ, Ligon LA. Electrospun nanofiber scaffolds for investigating cell-matrix adhesion. Methods Mol Biol. 2013;1046:371-388.

11. Jahani H, Kaviani S, Hassanpour-Ezatti M, Soleimani M, Kaviani Z, Zonoubi $Z$. The effect of aligned and random electrospun fibrous scaffolds on rat mesenchymal stem cell proliferation. Cell J. 2012;14(1): 31-38.

12. Szentivanyi A, Chakradeo T, Zernetsch H, Glasmacher B. Electrospun cellular microenvironments: understanding controlled release and scaffold structure. Adv Drug Deliv Rev. 2011;63(4-5):209-220.

13. Matthews JA, Wnek GE, Simpson DG, Bowlin GL. Electrospinning of collagen nanofibers. Biomacromolecules. 2002;3(2):232-238.

14. Thomas V, Zhang X, Vohra YK. A biomimetic tubular scaffold with spatially designed nanofibers of protein/PDS bio-blends. Biotechnol Bioeng. 2009;104(5):1025-1033.

15. Balasubramanian P, Prabhakaran MP, Kai D, Ramakrishna S. Human cardiomyocyte interaction with electrospun fibrinogen/gelatin nanofibers for myocardial regeneration. J Biomater Sci Polym Ed. 2013;24(14):1660-1675.

16. Duan H, Feng B, Guo X, et al. Engineering of epidermis skin grafts using electrospun nanofibrous gelatin/polycaprolactone membranes. Int J Nanomedicine. 2013;8:2077-2084.

17. Sreerekha PR, Menon D, Nair SV, Chennazhi KP. Fabrication of electrospun poly (lactide-co-glycolide)-fibrin multiscale scaffold for myocardial regeneration in vitro. Tissue Eng Part A. 2013;19(7-8): 849-859.

18. Li AD, Sun ZZ, Zhou M, et al. Electrospun chitosan-graft-PLGA nanofibres with significantly enhanced hydrophilicity and improved mechanical property. Colloids Surf B Biointerfaces. 2013;102: 674-681.

19. Sung HJ, Meredith C, Johnson C, Galis ZS. The effect of scaffold degradation rate on three-dimensional cell growth and angiogenesis. Biomaterials. 2004;25(26):5735-5742.

20. Zhang Y, Venugopal JR, El-Turki A, Ramakrishna S, Su B, Lim CT. Electrospun biomimetic nanocomposite nanofibers of hydroxyapatite/ chitosan for bone tissue engineering. Biomaterials. 2008;29(32): 4314-4322.

21. Jayakumar R, Prabaharan M, Nair SV, Tamura H. Novel chitin and chitosan nanofibers in biomedical applications. Biotechnol Adv. 2010;28(1):142-150.

22. Sarasam A, Madihally SV. Characterization of chitosan-polycaprolactone blends for tissue engineering applications. Biomaterials. 2005;26(27): 5500-5508.

23. Geng X, Kwon $\mathrm{OH}$, Jang J. Electrospinning of chitosan dissolved in concentrated acetic acid solution. Biomaterials. 2005;26(27): $5427-5432$. 
24. Borjigin M, Eskridge C, Niamat R, Strouse B, Bialk P, Kmiec EB. Electrospun fiber membranes enable proliferation of genetically modified cells. Int J Nanomedicine. 2013;8:855-864.

25. Dhiman HK, Ray AR, Panda AK. Three-dimensional chitosan scaffoldbased MCF-7 cell culture for the determination of the cytotoxicity of tamoxifen. Biomaterials. 2005;26(9):979-986.

26. Yang F, Both SK, Yang X, Walboomers XF, Jansen JA. Development of an electrospun nano-apatite/PCL composite membrane for GTR/ GBR application. Acta Biomater. 2009;5(9):3295-3304.

27. Chuthapisith S, Eremin J, El-Sheemey M, Eremin O. Breast cancer chemoresistance: emerging importance of cancer stem cells. Surg Oncol. 2010;19(1):27-32.

28. Lee HE, Kim JH, Kim YJ, et al. An increase in cancer stem cell population after primary systemic therapy is a poor prognostic factor in breast cancer. Br J Cancer. 2011;104(11):1730-1738.

29. Adamczyk A, Niemiec JA, Ambicka A, Mucha-Malecka A, Mitus J, Rys J. CD44/CD24 as potential prognostic markers in node-positive invasive ductal breast cancer patients treated with adjuvant chemotherapy. World J Surg Oncol. 2013;11:91.

30. Patel SA, Ramkissoon SH, Bryan M, et al. Delineation of breast cancer cell hierarchy identifies the subset responsible for dormancy. Sci Rep. 2012;2:906.

31. Dontu G, Abdallah WM, Foley JM, et al. In vitro propagation and transcriptional profiling of human mammary stem/progenitor cells. Genes Dev. 2003;17(10):1253-1270.

32. Borjigin M, Strouse B, Niamat RA, et al. Proliferation of genetically modified human cells on electrospun nanofiber scaffolds. Mol Ther Nucleic Acids. 2012;1:e59.

33. Bissell MJ. The differentiated state of normal and malignant cells or how to define a "normal" cell in culture. Int Rev Cytol. 1981;70:27-100.

34. Weigelt B, Bissell MJ. Unraveling the microenvironmental influences on the normal mammary gland and breast cancer. Semin Cancer Biol. 2008;18(5):311-321.

35. Bissell MJ, Radisky DC, Rizki A, Weaver VM, Petersen OW. The organizing principle: microenvironmental influences in the normal and malignant breast. Differentiation. 2002;70(9-10):537-546.
36. Saha S, Duan X, Wu L, Lo PK, Chen H, Wang Q. Electrospun fibrous scaffolds promote breast cancer cell alignment and epithelial-mesenchymal transition. Langmuir. 2012;28(4):2028-2034.

37. Fournier MV, Martin KJ, Kenny PA, et al. Gene expression signature in organized and growth-arrested mammary acini predicts good outcome in breast cancer. Cancer Res. 2006;66(14):7095-7102.

38. Anders M, Hansen R, Ding RX, Rauen KA, Bissell MJ, Korn WM. Disruption of 3D tissue integrity facilitates adenovirus infection by deregulating the coxsackievirus and adenovirus receptor. Proc Natl Acad Sci U S A. 2003;100(4):1943-1948.

39. Weaver VM, Lelievre S, Lakins JN, et al. beta4 integrin-dependent formation of polarized three-dimensional architecture confers resistance to apoptosis in normal and malignant mammary epithelium. Cancer Cell. 2002;2(3):205-216.

40. Gangopadhyay S, Nandy A, Hor P, Mukhopadhyay A. Breast cancer stem cells: a novel therapeutic target. Clin Breast Cancer. 2013;13(1): $7-15$.

41. Dickson RB, Deb TB. EGF receptor in breast cancer chemoresistance Adv Exp Med Biol. 2007;608:113-118.

42. Gan Y, Wientjes MG, Au JL. Expression of basic fibroblast growth factor correlates with resistance to paclitaxel in human patient tumors. Pharm Res. 2006;23(6):1324-1331.

43. Polini A, Scaglione S, Quarto R, Pisignano D. Composite electrospun nanofibers for influencing stem cell fate. Methods Mol Biol. 2013;1058 25-40.

44. Nadri S, Kazemi B, Eslaminejad MB, Yazdani S, Soleimani M. High yield of cells committed to the photoreceptor-like cells from conjunctiva mesenchymal stem cells on nanofibrous scaffolds. Mol Biol Rep. 2013;40(6):3883-3890.

45. Chen L, Xiao Z, Meng Y, et al. The enhancement of cancer stem cell properties of MCF-7 cells in 3D collagen scaffolds for modeling of cancer and anti-cancer drugs. Biomaterials. 2012;33(5):1437-1444.
International Journal of Nanomedicine

\section{Publish your work in this journal}

The International Journal of Nanomedicine is an international, peerreviewed journal focusing on the application of nanotechnology in diagnostics, therapeutics, and drug delivery systems throughout the biomedical field. This journal is indexed on PubMed Central,

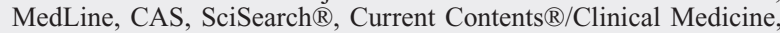

\section{Dovepress}

Journal Citation Reports/Science Edition, EMBase, Scopus and the Elsevier Bibliographic databases. The manuscript management system is completely online and includes a very quick and fair peer-review system, which is all easy to use. Visit http://www.dovepress.com/ testimonials.php to read real quotes from published authors. 